Research Article

\title{
Evaluation of Sonocatalytic and Photocatalytic Processes Efficiency for Degradation of Humic Compounds Using Synthesized Transition-Metal-Doped ZnO Nanoparticles in Aqueous Solution
}

\author{
Afshin Maleki $\left(\mathbb{D},{ }^{1}\right.$ Mehran Seifi $\mathbb{D}^{1},{ }^{1}$ and Nader Marzban $(\mathbb{D})^{2}$ \\ ${ }^{1}$ Environmental Health Research Center, Research Institute for Health Development, Kurdistan University of Medical Sciences, \\ Sanandaj, Iran \\ ${ }^{2}$ Leibniz Institute for Agricultural Engineering and Bioeconomy, Max-Eyth-Allee 100, Potsdam-Bornim 14469, Germany
}

Correspondence should be addressed to Afshin Maleki; maleki43@yahoo.com

Received 5 March 2021; Revised 13 April 2021; Accepted 19 April 2021; Published 23 April 2021

Academic Editor: Cláudia G. Silva

Copyright (C) 2021 Afshin Maleki et al. This is an open access article distributed under the Creative Commons Attribution License, which permits unrestricted use, distribution, and reproduction in any medium, provided the original work is properly cited.

\begin{abstract}
The existence of a humic substance in water causes the growth of microorganisms and reduces the quality of water; therefore, the removal of these materials is crucial. Here, the $\mathrm{ZnO}$ nanoparticles doped using transition metals, copper $(\mathrm{Cu})$ and manganese $(\mathrm{Mn})$, were used as an effective catalyst for photocatalytic removal of humic substances in an aqueous environment under ultraviolet, visible light, and light-emitting diode irradiations. Also, we study the effect of the sonocatalytic method. A solvothermal procedure is used for doping, and the $\mathrm{Cu}$ - and $\mathrm{Mn}$-doped $\mathrm{ZnO}$ nanocatalyst were characterized by means of FTIR, $\mathrm{XRD}, \mathrm{AFM}, \mathrm{SEM}$, and EDAX analyses. We investigate the effect of operational variables, including doping ratio, initial $\mathrm{pH}$, catalyst dose, initial HS content, and illuminance on the removal efficiency of the processes. The findings of the analyses used for the characterization of the nanoparticles illustrate the appropriate synthesis of the $\mathrm{Cu}$ - and $\mathrm{Mn}$-doped $\mathrm{ZnO}$ nanocatalysts. We observe the highest removal efficiency rate under acidic conditions and the process efficiency decreased with increasing solution $\mathrm{pH}$, when we tested it in the range of 3-7. Photocatalytic decomposition of HS increases with a rise in catalyst dose, but an increase in initial HS content results in decreasing the removal efficiency. We observe the highest photocatalytic degradation of humic acid while using the visible light, and the highest removal efficiency is obtained using $\mathrm{Cu}$.ZnO. The $\mathrm{Cu}$. ZnO also shows better performance under ultraviolet irradiation compared to other agents.
\end{abstract}

\section{Introduction}

Degradation of plants and animals by microorganisms in water can mainly result in humic substances (HSs), which are the major part of natural organic matters (NOMs) [1-3]. These materials can decline the quality of drinking water as they cause color, taste, and odor [4]. Moreover, water treatment facilities can be influenced by HSs because they can lead to membrane fouling and the growth of microorganisms in distribution systems. However, the most important problem with the presence of HSs in water is the formation of disinfection byproducts (DBPs) as the water is chlorinated [5]. Two major compounds of DBPs are trihalomethanes (THMs) and haloacetic acids (HAAs) [6]; it has been documented that these compounds have carcinogenic and mutagenic properties [7]. Hence, it is of greatest importance to treat water containing HSs.

Several methods like the coagulation process [8], membrane technology [9], adsorption processes [10], and advanced oxidation processes (AOPs) have been employed to remove HSs from the aqueous solution. In AOPs, the hydroxyl radical of $\mathrm{OH} \bullet$ as the strongest oxidizing agent is generated, which can degrade both organic and inorganic matters [11]. Recently, ultrasonic energy has been applied to generate the $\mathrm{OH}$ radicals to degrade refractory organic compounds. In aqueous solutions, ultrasonic irradiation can 
lead to producing cavitation bubbles because of acoustic cavitation. As a result, the produced bubbles generate severe heat and pressure in solution, called the "hot spots" phenomenon, because of which water molecules are pyrolyzed and $\mathrm{OH} \bullet$ is generated $[12,13]$.

Photocatalytic methods have commonly been applied for the degradation of pollutants in water $[14,15]$. The TiO2 and $\mathrm{ZnO}$ are two semiconductors, which have widely been used as a catalyst to decompose a huge number of resistant environmental contaminants in the presence of UV irradiation $[16,17]$. In comparison with $\mathrm{TiO} 2$, the $\mathrm{ZnO}$ nanocatalyst has been introduced as a better photocatalyst because of its prominent advantages like wide bandgap, cheapness, high stability, and high adsorption capacity in UV irradiation [18-21]. Although $\mathrm{ZnO}$ benefits from several plus factors, its photocatalytic activity is activated just under UV light (5 to $7 \%$ of solar energy), which makes it impossible to be used as the natural activation source [22]. In addition, another drawback to $\mathrm{ZnO}$ nanoparticles is a quick recombination of hole-electron pairs [23]. Therefore, in order to enhance the photocatalytic performance of $\mathrm{ZnO}$ nanoparticles, the mentioned problems should be solved. As a whole, irradiation via ultraviolet (UV) or visible light (VL) to the surface of semiconductors can trigger photocatalytic reactions, thereby exciting electrons from the valence band and transferring them to the conduction band [24]. As a result, the produced hole-electron $(\mathrm{h} / \mathrm{e})$ pair at the catalyst level can oxidize contaminant molecules through generating more $\mathrm{OH} \bullet$; this results in more oxidation and regeneration reactions [22].

Recently, the doping of the $\mathrm{ZnO}$ nanoparticles using transition metals like manganese $(\mathrm{Mn})$, iron $(\mathrm{Fe})$, copper $(\mathrm{Cu})$, and so on has been introduced as a beneficial method [25]. It is worth noting that if a proper dopant is used, the bandgap energy of $\mathrm{ZnO}$ changes, thereby preventing the recombination of charge carriers. The doping of $\mathrm{ZnO}$ using a transition metal produces new electron levels; this makes it possible for $\mathrm{ZnO}$ to absorb visible light [26]. When $\mathrm{ZnO}$ is doped by a metal ion, the generated light electrons are trapped and penetrate to its structure, thereby increasing the photocatalytic performance of the doped $\mathrm{ZnO}$ nanoparticles. Chang et al. stated that the application of the Ce-doped $\mathrm{ZnO}$ photocatalyst could beneficially degrade dyes: direct blue 86 , food black-2, and methyl orange under UV and visible light irradiation [27]. Also, the results reported by Subash et al. showed that the synthesized Ce codoped $\mathrm{Ag}-\mathrm{ZnO}$ photocatalyst could effectively degrade Naphthol Blue Black (NBB) dye under natural sunlight illumination [28]. The application of ultrasonic irradiation generates microjets stemming from the collapse of cavitation bubbles in the solution; this causes the solution to be stirred well. Moreover, it can resolve the major downside of UV-lightbased photocatalytic methods suffering from low penetration amount of UV light and shielding effects of nanoparticles [29].

Currently, there are a few research studies of copperdoped and manganese-doped $\mathrm{ZnO}$ nanocomposites for sonocatalytic and photocatalytic applications as well as HS decomposition by doped nanocatalysts in the aqueous environment. However, to the best of our knowledge, there are no reports on the sonocatalytic and photocatalytic decomposition of HS by manganese and copper doped $\mathrm{ZnO}$ nanocatalysts synthesized by the hydrothermal method. Therefore, in this study, two transition-metal ions, copper $(\mathrm{Cu})$ and manganese $(\mathrm{Mn})$, were selected because researchers have shown that copper is an inexpensive element that has physical and chemical properties similar to the properties of zinc. Therefore, due to the mismatch of the minimum size between zinc and copper, it is the best choice as an impurity for the realization of $\mathrm{ZnO}$, which leads to the lowest formation energy. Also, due to its close size to zinc, it can be easily placed in the $\mathrm{ZnO}$ crystal lattice and change the microstructure and optical properties of $\mathrm{ZnO}$. Also, due to its close size to zinc, it can be easily placed in the $\mathrm{ZnO}$ crystal lattice, altering the microstructure and optical properties of $\mathrm{ZnO}$ and showing a significant redshift in light absorption wavelength followed by an excellent catalytic activity [30-32]. In the same way, it has been shown that the use of $3 \mathrm{~d}$ metal ions such as Mn with half-filled electronic configuration properties as dopants can increase the surface area and reduce the size of nanoparticles, including zinc oxide nanoparticles. This is why the use of $\mathrm{Mn}$ for $\mathrm{ZnO}$ doping is preferred because the d-manganese electron at the $t 2 \mathrm{~g}$ level can easily overlap with the ZnO's valence bond compared to other transition elements. In addition, manganese will not only act as a recombination center but also create more intermediate states. As a result, it shows a significant shift in the absorption and emission spectra to the visible light region $[33,34]$. Therefore, according to the existing documents and the importance of the subject, this study was performed to synthesize zinc oxide by solvothermal method with the aim of improving its catalytic properties. Humic acids (HAs) as the target pollutant as well as an important chemical compound which is a pervasive substance in the environment, a natural refractory organic matter, and an important carcinogenic precursor in water supply was considered in this study and the efficiency of synthesized doped nanoparticles including $\mathrm{ZnO}, \mathrm{Cu} . \mathrm{ZnO}, \mathrm{Mn} . \mathrm{ZnO}$, and Cu.Mn.ZnO in its catalytic degradation under ultraviolet irradiation, ultrasound radiation, LED, and visible light illumination was determined and evaluated. The effect of dopants concentration, solution $\mathrm{pH}$, catalyst dosage, initial HAs concentration, and contact time on the degradation process of HAs and optical properties of nanoparticles was also investigated.

\section{Materials and Methods}

2.1. Chemicals. In the current research, the humic substance was purchased from Sigma-Aldrich Co. (Germany) and used as the model contaminant. The other materials used were of analytical grade and bought from Merck (Germany). Also, distilled water was applied for the preparation of synthetic solutions, as well as other experiments. Moreover, $\mathrm{NaOH}$ and $\mathrm{H}_{2} \mathrm{SO}_{4}$ were used to adjust the $\mathrm{pH}$ of the solutions.

2.2. Reactor. All the experiments were conducted by using a closed system, a $250 \mathrm{ml}$ glassy reactor. Five $15 \mathrm{~W}$ UV lamps (Philips, Netherlands) were placed on the top part of the 
reactor to provide the UV region for the photocatalytic degradation runs. Meanwhile, to provide the visible region, natural sunlight (visible light (VL)) and light-emitting diode (LED) light (20-watt LED lamp) were applied as light sources. It should be noted that the visible light-based experiments were conducted in the peak hours of sunshine. Also, an Elema ultrasonic device (Germany) was utilized for the sonocatalytic process at 37 and $80 \mathrm{kHz}$ frequency and $100 \%$ power. Furthermore, a magnetic stirrer was utilized in order to well mix the solution inside the reactor.

2.3. Photocatalyst Synthesis. In this study, a solvothermal procedure was exerted to dope the $\mathrm{ZnO}$ nanocatalysts with $\mathrm{Cu}$ and $\mathrm{Mn}$. To prepare the undoped $\mathrm{ZnO}$ product, first, $119 \mathrm{~g} / \mathrm{l}(0.4 \mathrm{M})$ hexahydrate zinc nitrate and $54.18 \mathrm{~g} / \mathrm{L}$ $(0.6 \mathrm{M})$ oxalic acid were dissolved separately in $100 \mathrm{ml}$ deionized water and heated to the boiling point of the solutions. Next, the solution containing oxalic acid was added dropwise to the $\mathrm{Zn}$ (NO3) 2 solution. Then, the new solution was shaken and stirred well for $1 \mathrm{~h}$, at $65^{\circ} \mathrm{C}$; afterwards, it was cooled at room temperature. Then, the obtained homogeneous $\mathrm{ZnO}$ particles were washed a few times using distilled water; the mixture was then placed in an oven for $5 \mathrm{~h}\left(100^{\circ} \mathrm{C}\right)$ to dry it. In order to synthesize $\mathrm{Cu}$-doped $\mathrm{ZnO} \mathrm{NPs}$ and $\mathrm{Mn}$ doped $\mathrm{ZnO}$ NPs (with a dopant concentration of $2 \%$ ), $0.2 \mathrm{M}$ $\mathrm{Cu}\left(\mathrm{CH}_{3} \mathrm{COO}\right)_{2}$ and $0.24 \mathrm{M} \mathrm{Mn}(\mathrm{CH} 3 \mathrm{COO})_{2} \cdot 4 \mathrm{H}_{2} \mathrm{O}$ were added to the $\mathrm{ZnO}$ solution; in the next stage, oxalic acid was added, and the procedure for the synthesis was repeated like that for the undoped nanoparticles. To synthesize other percentages of the dopants: 1.5 and $2.5 \%$ for the two metals, 0.15 and $0.25 \mathrm{M} \mathrm{Cu}$ and 0.18 and $0.3 \mathrm{M} \mathrm{Mn}$ were applied according to the method explained above. And, for the synthesis of the codoped $\mathrm{ZnO}$ nanocatalyst, the aforementioned method was followed [28].

2.4. Characterization of Nanoparticles. In order to characterize the NPs synthesized in this study, scanning electron microscopy (SEM), X-ray diffraction (XRD), Fourier transform infrared (FTIR) spectroscopy, dynamic light scattering (DLS), atomic force microscopy (AFM), and zeta potential were used. To this end, a TESCAN microscope (model MIRA3, Czech Republic) was utilized to explain the shape and size of the ZnO NPs. In the present study, in order to obtain the information on the phase composition of the photocatalyst, especially the thin coating layer composited of $\mathrm{ZnO}$, through an Inel instrument (EQUINOX 3000, France). Furthermore, a Bruker Tensor 27 instrument (Germany) was used for the FTIR spectroscopy of the synthesized NPs. And an AFM microscope (Advance model, Iran) was employed for the determination of the surface morphology of the NPs. Finally, the size of the NPs was determined via a DLS analyzer (NanoBrook model, USA).

2.5. Photocatalytic Experiments. The removal efficiency of the as-synthesized nanoparticles was examined by determining the degradation rate of humic acid. First, a 1,000 mg/ L stock solution of humic acid was prepared by distilled water and then kept at $4^{\circ} \mathrm{C}$. And the working solutions were made daily through diluting the stock solution in deionized water. In order to measure the content of humic acid before and after experiments, a UV-vis spectrophotometer was used at the maximum absorbance wavelength $(\lambda \max )$ of $254 \mathrm{~nm}$. The number of samples was calculated according to the number of photocatalytic experiments, and the method of one factor at one time was used to optimize the parameters. The effect of the photocatalytic method on humic acid was measured in the presence of UV irradiation, sunlight, LED light, and ultrasound waves. Furthermore, the operating parameters: nanocatalyst type; dopant percentage, $1.5,2$, and 2.5\%; initial humic acid content, $5,10,20,30,40$, and $50 \mathrm{mg} / \mathrm{L} ; \mathrm{pH}$ value, $3,5,7$, and 9; catalyst dosage, $0.4,2$, 4,6 , and $8 \mathrm{~g} / \mathrm{L}$; and reaction time, $15-180 \mathrm{~min}$, were examined.

\section{Results and Discussion}

3.1. Cu.ZnO Nanoparticle Characterization. As previously mentioned, in the present study, the surface properties of the synthesized $\mathrm{Cu} . \mathrm{ZnO}$ NPs were characterized by using the SEM analysis. Furthermore, Digimizer, which is an image analysis software, was used to determine the particle size distribution of the nanoparticles. Figure 1 shows the SEM image and particle size of the proposed photocatalyst. The SEM analysis shows a high and porous surface for the synthesized photocatalyst. As can be observed from the figure, the mean diameter of particle size distribution was $74.2 \pm 21 \mathrm{~nm}$. Therefore, it is illustrated that the synthesized nanoparticles had an approximately uniform spherical form with no agglomeration.

The chemical composition of the pure and $\mathrm{Cu}$ doped $\mathrm{ZnO}$ nanoparticles was performed using EDAX analysis and their results are displayed in Figure 2. The EDAX spectra of pure $\mathrm{ZnO}$ show $\mathrm{Zn}$ and $\mathrm{O}$ elements. The atomic ratio of $\mathrm{Zn}$ and $\mathrm{O}$ ions in the pure $\mathrm{ZnO}$ sample was 51.19 and 48.81 which is close to $1: 1$ ratio. In the $2 \% \mathrm{Cu}$-doped $\mathrm{ZnO}$ sample, the atomic concentrations of $\mathrm{Cu}, \mathrm{Zn}$, and $\mathrm{O}$ are 3.79, 76.59, and $19.62 \%$, respectively. Therefore, EDAX analysis confirms the presence of $\mathrm{Cu}$ in the $\mathrm{ZnO}$ system and their weight percentage is approximately equal to their nominal stoichiometry under experimental conditions. These results also show that the zinc content in the undoped $\mathrm{ZnO}$ nanoparticles decreases simultaneously after doping with $\mathrm{Cu}$, but the $\mathrm{Cu}$ content of $\mathrm{Cu}$-doped $\mathrm{ZnO}$ increased significantly from 0 to 3.79 (wt\%), indicating successful copper deposition in the structure of nanoparticles.

FTIR is a tool applied to attain information on the chemical bonding in a compound. Figure 3 presents the FTIR spectra of the synthesized nanoparticles. In all the samples studied, we observed broad absorption peaks at around 3700 and $1000 \mathrm{~cm}^{-1}$, which are attributed to normal polymeric $\mathrm{O}-\mathrm{H}$ stretching vibration of $\mathrm{H}_{2} \mathrm{O}$ in $\mathrm{Cu}-\mathrm{Zn}-\mathrm{O}$ lattice [23], which may be because of moisture in solution and atmosphere. We also observed a sharp peak around $2750 \mathrm{~cm}^{1}$, which is ascribed to $\mathrm{H}-\mathrm{O}-\mathrm{H}$ bending vibration attributed to a small amount of $\mathrm{H}_{2} \mathrm{O}$ in the $\mathrm{ZnO}$ nanocrystals [25]. 


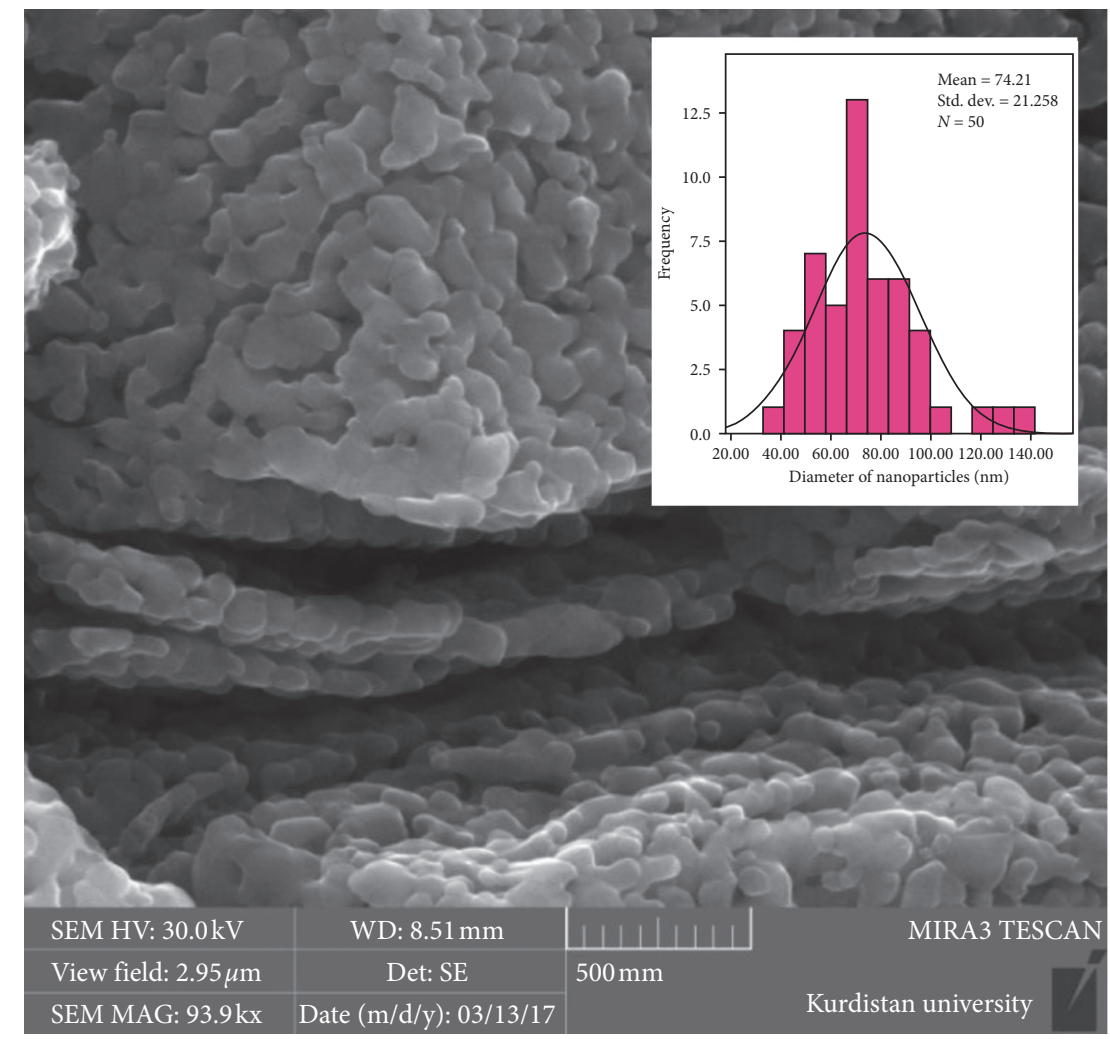

Figure 1: SEM images and size distribution of the Cu.ZnO NPs.
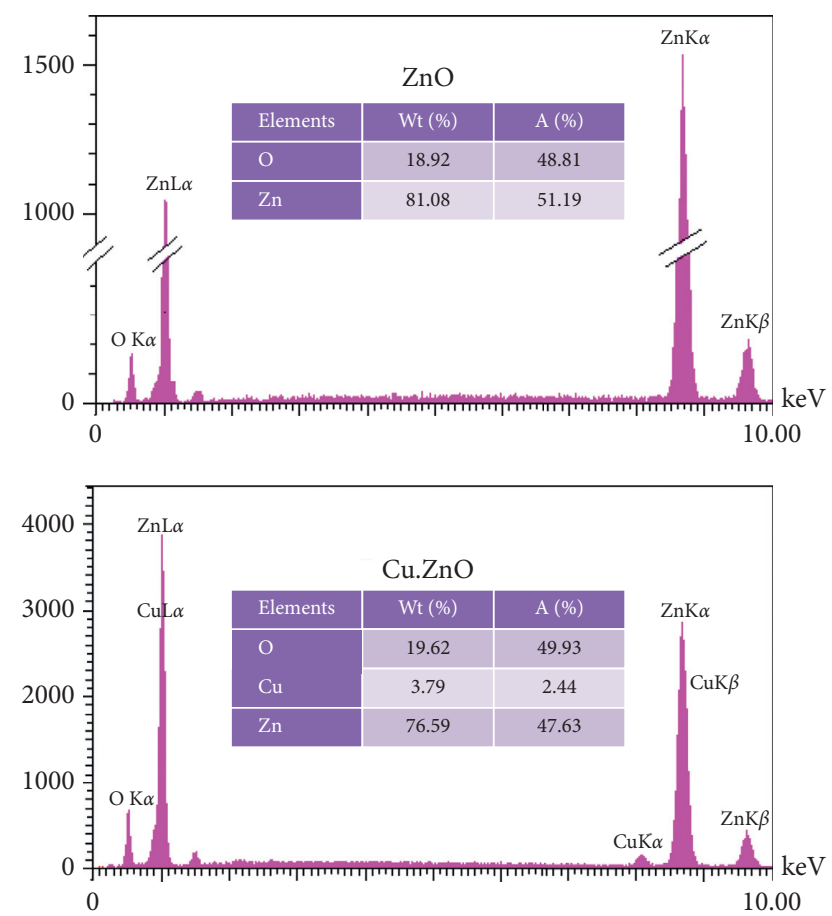

Figure 2: EDAX spectra of undoped $\mathrm{ZnO}$ and $\mathrm{Cu}$-doped $\mathrm{ZnO}$ NPs.

Figure 4 shows the XRD patterns of the synthesized nanoparticles. It has been reported that recrystallization and grain coarsening is formed because of the heat treatment process in amorphous materials. This phenomenon could

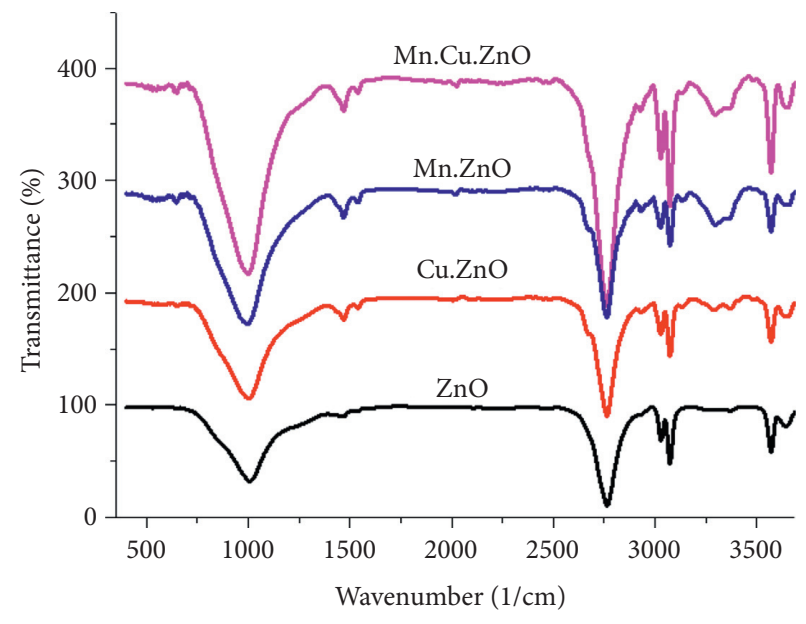

Figure 3: FTIR spectra of the synthesized NPs.

lead to the emergence of peaks in the XRD pattern [35]. Apparently, the XRD patterns of all the synthesized nanoparticles: $\mathrm{ZnO}, \mathrm{Cu} . \mathrm{ZnO}$, and $\mathrm{Mn} . \mathrm{ZnO}$ had three major peaks: (100), (102), and (101), which are related to crystal planes (Figure 3). As can be seen, the three peaks accord with the pure $\mathrm{ZnO}$ nanoparticles' peak (JCPDS stand card no. 800075), illustrating hexagonal crystal lattice. Furthermore, the patterns do not show an impurity phase, which accords with the two dopant metals. Nonetheless, the presence of the $\mathrm{Cu}$ and $\mathrm{Mn}$ leads to a shift of the three peaks because $\mathrm{Zn}^{2+}$ ions are substituted by these metals having larger effectual ionic radii and expansion of the lattice network. 


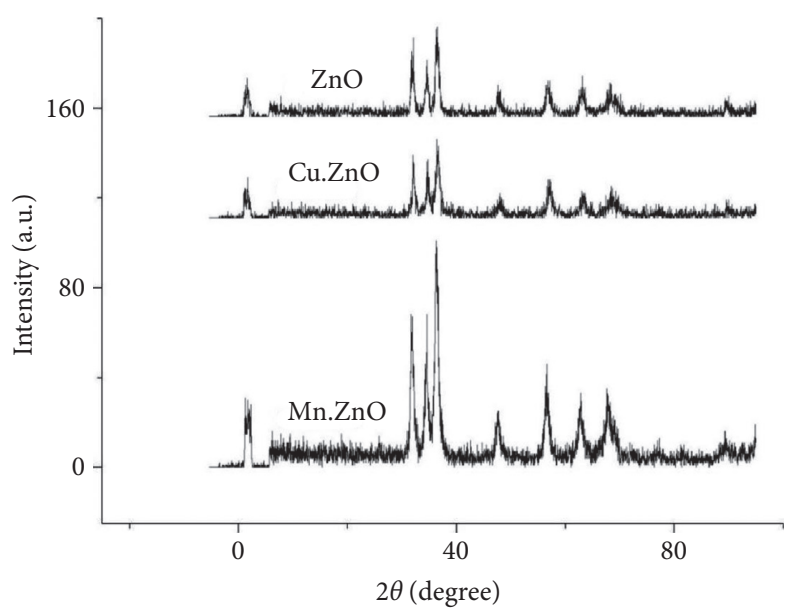

FIGURE 4: XRD patterns of the synthesized nanoparticles.

Here, we applied the Dynamic light scattering as a physical method to determine the distribution of nanocatalyst particles in the solution and Figure 5(a) shows the results. We observed that the size of the most efficient synthesized nanoparticle is between 150 and $200 \mathrm{~nm}$ and also has a uniform distribution in this size range. In addition, the Zeta potential can be used as the main tool to study the electric charge at the interface of colloids. For this purpose, the zeta potential of the most efficient synthesized nanoparticle was also determined. Figure 5(b) shows that nanoparticle doping has increased the zeta potential compared to the undoped nanoparticle.

$\mathrm{UV}$-vis spectra of the synthesized nanoparticles were performed to confirm the formation of $\mathrm{ZnO} \mathrm{NP}$ and to compare the doped nanoparticles in terms of light absorption and its result is shown in Figure 6. As can be seen from this figure, a strong absorption band of about $371 \mathrm{~nm}$ can be seen, which confirms the formation of $\mathrm{ZnO} N P s$. This sharp peak indicates that firstly, the particle size distribution is narrow and, secondly, the particle size is at the nanoscale [36, 37]. Zack et al. [37] obtained similar findings that confirm the formation of $\mathrm{ZnO}$ in this study. In the case of synthesized doped nanoparticles, it is also clear that all of them can effectively absorb light and develop the photocatalytic process under visible light. From these results, the absorption edge of $\mathrm{Cu} . \mathrm{ZnO}$ and $\mathrm{Mn} . \mathrm{ZnO}$ NPs are 390 and $383 \mathrm{~nm}$, respectively, and it can be seen that the absorption peak is shifted to a longer wavelength. This slight redshift in the structure of $\mathrm{Mn} . \mathrm{ZnO}$ and $\mathrm{Cu} . \mathrm{ZnO}$ is due to the doping of $\mathrm{Mn}$ and $\mathrm{Cu}$ into the crystal lattice of $\mathrm{Zn}$, which increases the absorption ability of the doped nanoparticles and then enhances better photoactivity. Comparing the data of UVvis spectroscopy with the efficiency of different removal processes, as shown in Figure 6, it is clear that the photocatalytic efficiency of the doped nanoparticles is increased compared to pure $\mathrm{ZnO}$, which indicates an improvement in visible light absorption due to the reduction of the $\mathrm{ZnO}$ bandgap.

The AFM analysis is applied to determine the size of NPs. This technique provides information regarding the roughness of $\mathrm{ZnO}$ NPs [38]. Roughness average, $\mathrm{Ra}$, is the arithmetic average of the absolute values of the profile heights over the evaluation length. RMS roughness, $\mathrm{Rq}$, is the root mean square average of the profile heights over the evaluation length. Here, we applied the AFM analysis to observe the shape of the $\mathrm{ZnO}$ NPs using tip-corrected AFM measurements (Figure 7). According to the results, the values of the $\mathrm{Ra}$ and $\mathrm{Rq}$ were 10.03 and $11.05 \mathrm{~nm}$, respectively.

The effects of the different agents such as $\mathrm{ZnO}, \mathrm{Cu} . \mathrm{ZnO}$, $\mathrm{Mn} . \mathrm{ZnO}$, and $\mathrm{Mn} . \mathrm{Cu} . \mathrm{ZnO}$ on the removal efficiency were investigated. Furthermore, we compared the removal efficiency of these agents with the process in which no catalyst was used. As Figure 8 shows, the highest efficiency is related to the $\mathrm{Cu} . \mathrm{ZnO}$ catalyst in the presence of visible light, followed by UV irradiation. This shows the effect of visible light and UV on the synthesized catalyst for more production of hydroxyl radicals. The produced radicals can directly take part in the degradation of humic acid. In contrast, we observed the lowest efficiency in the case of lack of a catalyst in all the processes. In order to evaluate the effect of different nanocatalysts on the decomposition of HAs by using different catalytic processes, the results of this study are compared with other reported data and summarized in Table 1. This comparison shows that the metals-doped $\mathrm{ZnO}$ is an effective catalyst for the degradation of HAs compared to other photocatalysts.

\subsection{Effect of Dopant Percentage and Irradiation Type Source.} In the next step, we investigated the influences of ultrasonic, LED light, UV irradiation, and visible light on the removal of humic acid using the $\mathrm{Cu} . \mathrm{ZnO}$ nanoparticles. It has been documented that, to enhance the performance of photocatalysts, semiconductors can be modified by a doping species (transitional metals). It is due to the fact that the optical response of the photocatalyst is shifted to higher wavelengths, which makes the photocatalyst active under visible irradiation. In this case, sunlight can be used as a cheap energy source for irradiation. In addition to optical absorption, some other characteristics of the photocatalyst like surface area, hydroxyl group density, adsorption/ 


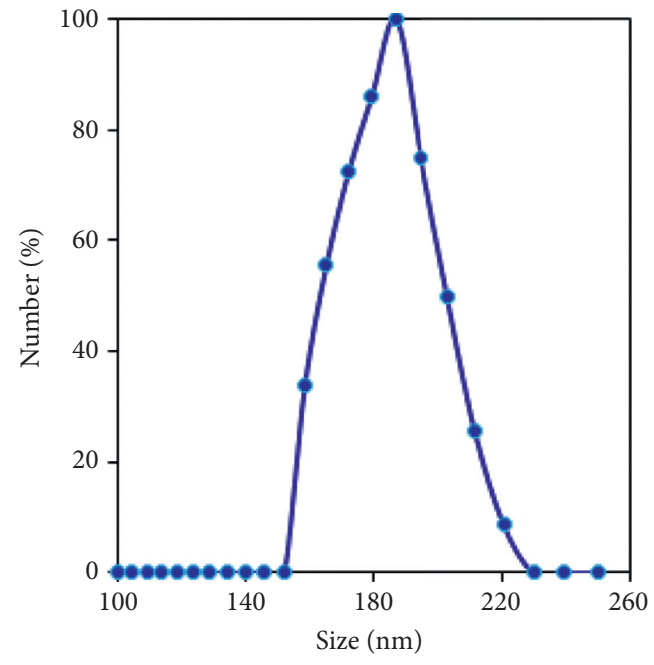

(a)

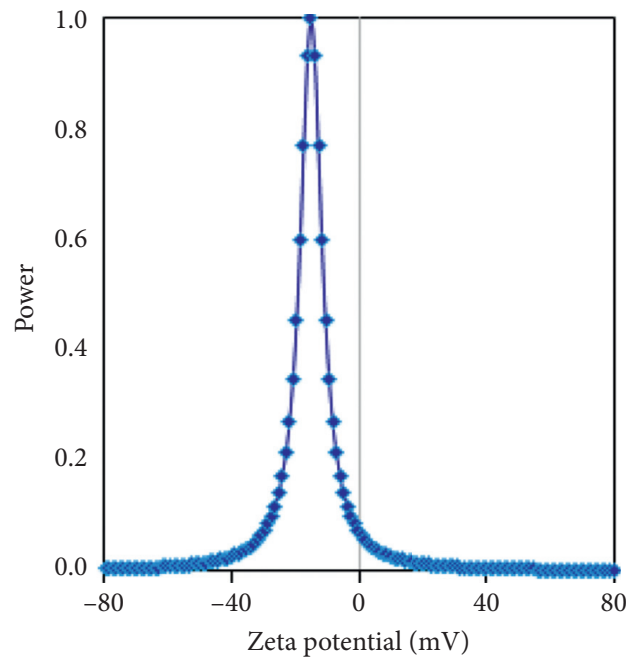

(b)

Figure 5: DLS results (a) and Zeta potential- ELS method (b) of the Cu.ZnO nanoparticles.

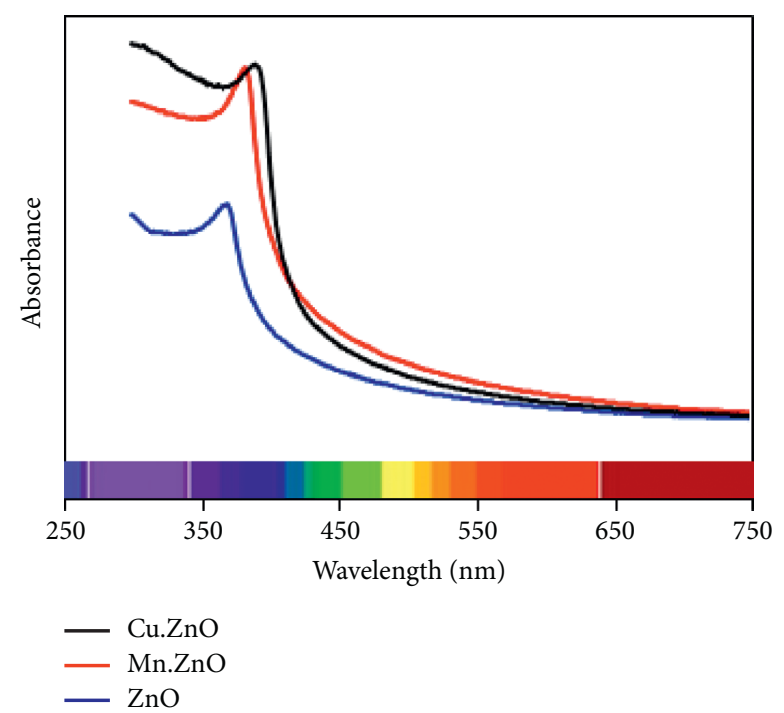

Figure 6: UV-vis absorption spectra of $\mathrm{ZnO}, \mathrm{Mn}$ doped $\mathrm{ZnO}$, and $\mathrm{Cu}$ doped $\mathrm{ZnO}$ nanoparticles.

desorption, and so on can improve. It should be pointed out that the highest degradation rate of dyes happens at the optimum level of transition metals; this is because of the fact that the ions of copper deposit on the photocatalyst particles. As a result, oxygen vacancies are produced on the photocatalyst surface, thereby trapping the photogenerated electrons $[47,48]$. On the other hand, when the content of dopant ions exceeds the optimum level, extra oxygen vacancies and $\mathrm{Cu}$ ions can recombine photoinduced electrons and holes; all this leads to decreasing the photocatalytic performance of the photocatalyst [47]. Moreover, when there are a higher number of dopants, extra ions of which deposit on the surface of photocatalyst particles instead of diffusing into photocatalyst lattice; this hinders the penetration of UV light and, in turn, active sites of the catalyst are blocked [48]. Of course, these changes depend on various factors, including the type of dopant and its concentration.
In the case of manganese, it has been shown that, as the percentage of manganese increases, the particle size of $\mathrm{ZnO}$ nanoparticles also increases because the agglomeration of particles probably occurs. Therefore, at high concentrations of $\mathrm{Mn}$, it is very difficult to incorporate into the crystal lattice of $\mathrm{ZnO}$. Hence, it is recommended that the appropriate $\mathrm{Mn}$ concentration be accurately determined and that lower dopant concentration be used to create smaller particles and prevent particle aggregation [33].

Figure 9 shows the effect of the mentioned agents on the process efficiency. As can be seen, the visible light had the most effect on the photocatalysis of humic acid, and the highest removal efficiency was obtained using the $\mathrm{ZnO}$ doped by 2.5 and $2 \% \mathrm{Cu}$, respectively, in the presence of visible light. The single $\mathrm{Cu} . \mathrm{ZnO}$ had the lowest performance under UV irradiation. We also observed the same trend for all the other activation agents, such as ultrasonic, LED, and 

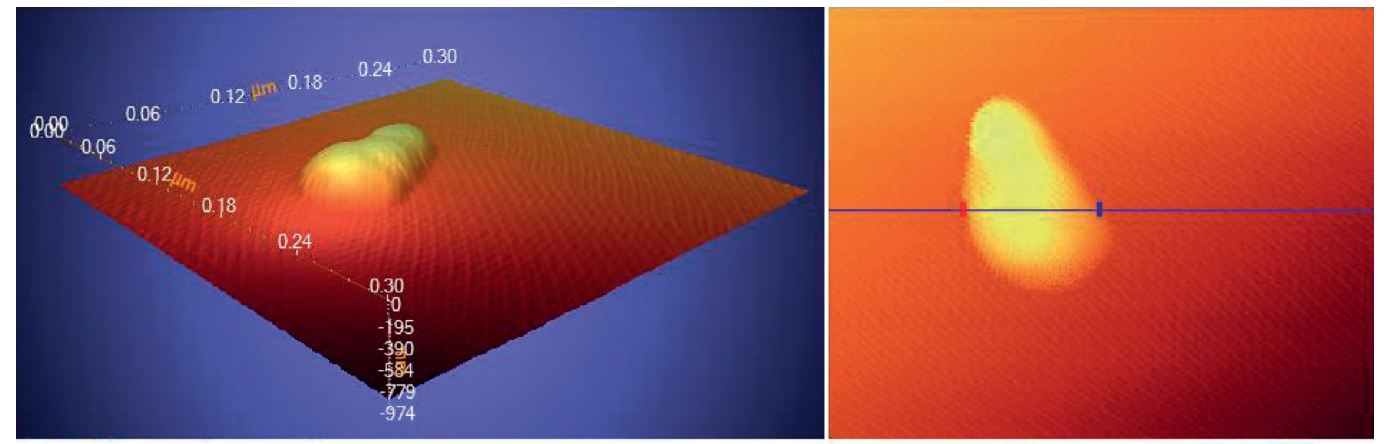

\begin{tabular}{|l|c|c|}
\hline $\mathrm{X}$ & 0.08 & $\mu \mathrm{m}$ \\
\hline $\mathrm{Y}$ & 0.16 & $\mu \mathrm{m}$ \\
\hline $\mathrm{Z}$ & -954.84 & $n \mathrm{~m}$ \\
\hline $\mathrm{X}$ & 0.15 & $\mu \mathrm{m}$ \\
\hline $\mathrm{Y}$ & 0.16 & $\mu \mathrm{m}$ \\
\hline $\mathrm{Z}$ & -955.99 & $n \mathrm{~m}$ \\
\hline $\mathrm{dX}$ & -0.07 & $\mu \mathrm{m}$ \\
\hline $\mathrm{d} Y$ & 0 & $\mu \mathrm{m}$ \\
\hline $\mathrm{d} Z$ & 1.15 & $\mathrm{~nm}$ \\
\hline $\mathrm{dXY}$ & 0.07 & $\mu \mathrm{m}$ \\
\hline $\mathrm{dXYZ}$ & 1.15 & $\mu \mathrm{m}$ \\
\hline
\end{tabular}

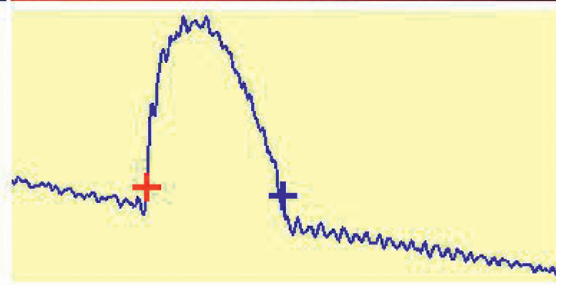

Figure 7: The AFM image of the Cu.ZnO NPs. Comparison of different processes on the removal efficiency of humic acid.

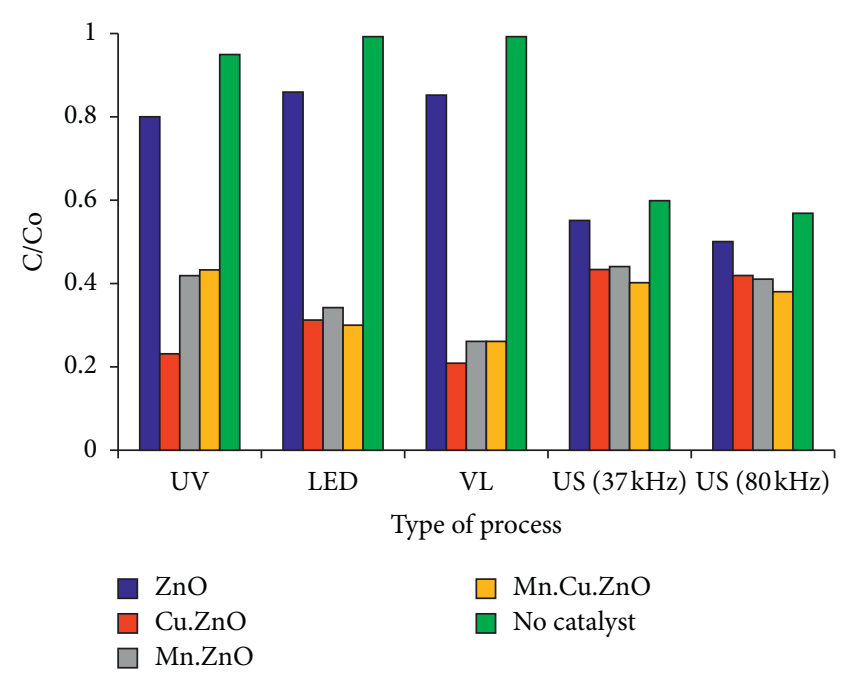

FIgURE 8: Comparison of the methods tested in this study including photocatalytic processes: natural sunlight and LED light and sonocatalytic processes: 37 and $80 \mathrm{KHz}$ under the following conditions: contact time $=90 \mathrm{~min}$, humic acid concentration $=20 \mathrm{mg} /$ $\mathrm{L}, \mathrm{pH}=7$, nanocatalyst dosage $=2 \mathrm{~g} / \mathrm{L}$, and dopant percentage $=2 \%$.

visible light. Among the used activation agents, visible light had the highest effect on the process efficiency and provided more efficiency for the removal of humic acid. These differences in the effects of the used agents are associated with the absorbance edges of the prepared catalyst that can effectively activate the catalyst compared to the other agents. These results are consistent with the findings of previous studies. For example, Taufik et al. reported that ternary $\mathrm{CuO} /$ $\mathrm{TiO}_{2} / \mathrm{ZnO}$ nanocomposites offered a high performance (approximately 100\%) under UV irradiation and visible light [49]. In general, in this study, the processes in which ultrasonic waves were utilized for the activation of the NPs had lower performance than the other methods. Geng et al. stated that the sole application of the ultrasonic irradiation process in contaminant removal needs long contact time and high energy consumption, which causes the performance to decline [50].

We have discussed and concluded that the synthesized $\mathrm{Cu} . \mathrm{ZnO}$ nanoparticles showed the best performance in humic acid degradation. Next, the effects of various operational parameters such as solution $\mathrm{pH}$, pollutant concentration, nanocatalyst dosage, and contact time on the process efficacy were investigated.

3.2.1. Effect of Solution $p H$. Figure 10(a) shows the influence of solution $\mathrm{pH}$ on performing the proposed process for the removal of HS at two different contact times. As observed, the highest removal efficiency was obtained under acidic conditions and the process efficiency decreased with increasing solution $\mathrm{pH}$ in the range of 3-7. We observed the lowest removal efficiency at $\mathrm{pH}$ values of 7 and 9 .

The solution $\mathrm{pH}$ can affect photocatalyst removal efficiency by affecting the functional groups of humic acids and catalyst surface. Because humic acid contains both hydrophobic and hydrophilic functional groups, including carboxyl, phenolic hydroxyl, alcoholic hydroxyl, and carbonyl forms, under alkaline conditions, the adsorption of humic acid on the catalyst surface is very weak due to the high repulsion of carboxylate ions by negatively charged photocatalyst surface $[51,52]$.

In a previous study, it has been stated that the $\mathrm{pH}_{\mathrm{PZC}}$ of the ZnO NPs was 9.8, which makes its surface positively charged at $\mathrm{pH}$ values less than the PZC (acidic conditions) [53]. Thus, it is expected to attain a high catalytic performance for the photocatalytic degradation of humic acid. The results obtained in the current research are consistent with the findings reported by [54]. 
TABle 1: Comparison of different systems of photocatalytic degradation of HAs.

\begin{tabular}{|c|c|c|c|c|c|c|c|}
\hline Photocatalyst & $\begin{array}{l}\text { Dosage } \\
(\mathrm{g} / \mathrm{l})\end{array}$ & Energy source & Time (min) & $\begin{array}{l}\text { Concentration } \\
(\mathrm{mg} / \mathrm{l})\end{array}$ & $p \mathrm{H}$ & Removal (\%) & Reference \\
\hline $\mathrm{Fe}-\mathrm{Zn}$ codoped $\mathrm{TiO}_{2}$ & 0.1 & $\begin{array}{c}7 \mathrm{~W} \text { low-pressure mercury vapor } \\
\text { lamp }\end{array}$ & 120 & 50 & 2 & 65.7 & {$[39]$} \\
\hline $\mathrm{TiO}_{2} \mathrm{P} 25$ & 1 & Vapor xenon lamp & 240 & 100 & 3 & 100 & {$[40]$} \\
\hline Fe-doped $\mathrm{TiO}_{2} @ \mathrm{Fe}_{3} \mathrm{O}_{4}$ & 0.4 & $15 \mathrm{~W}$ bare UVC lamp & 60 & 5 & 3 & 70 & {$[41]$} \\
\hline$N$-doped $\mathrm{TiO}_{2}$ & 0.1 & Elma ultrasonic bath $-130 \mathrm{kHz}$ & 90 & 20 & - & 68 & {$[42]$} \\
\hline $\mathrm{MgO}$ & 1 & $130 \mathrm{kHz}$ & 120 & 20 & 7 & 78.5 & {$[43]$} \\
\hline $\mathrm{Ag} / \mathrm{ZnO}$ & 0.6 & Philips lamp $(400 \mathrm{~W})$ & 40 & 50 & 7 & 70 & {$[44]$} \\
\hline Metal-doped $\mathrm{TiO}_{2}$ & 0.5 & Black light blue (BLB) lamp (20 W) & 120 & 20 & - & $70-80$ & {$[45]$} \\
\hline $\begin{array}{l}\mathrm{TiO} 2 / \mathrm{ZnO} \\
\text { nanocomposite }\end{array}$ & 0.8 & Hg lamp (15 W) & 180 & 25 & & 89 & {$[46]$} \\
\hline $\mathrm{Cu}$-doped $\mathrm{ZnO}$ & 2 & 15 W UV lamps & 90 & 20 & 7 & 77 & This study \\
\hline $\mathrm{Cu}$-doped $\mathrm{ZnO}$ & 2 & Sunlight & 90 & 20 & 7 & 79 & This study \\
\hline $\mathrm{Cu}$-doped $\mathrm{ZnO}$ & 2 & Elma ultrasonic bath- 37 and $80 \mathrm{kHz}$ & 90 & 20 & 7 & $57 / 58$ & This study \\
\hline $\mathrm{Cu}$-doped $\mathrm{ZnO}$ & 2 & 20-watt LED lamp & 90 & 20 & 7 & 69 & This study \\
\hline Mn-doped $\mathrm{ZnO}$ & 2 & $15 \mathrm{~W}$ UV lamps & 90 & 20 & 7 & 58 & This study \\
\hline $\mathrm{Mn}$-doped $\mathrm{ZnO}$ & 2 & Sunlight & 90 & 20 & 7 & 74 & This study \\
\hline $\mathrm{Mn}$-doped $\mathrm{ZnO}$ & 2 & Elma ultrasonic bath-37 and $80 \mathrm{kHz}$ & 90 & 20 & 7 & $56 / 59$ & This study \\
\hline Mn-doped $\mathrm{ZnO}$ & 2 & 20 Watt LED lamp & 90 & 20 & 7 & 66 & This study \\
\hline $\mathrm{Cu}$. Mn-doped $\mathrm{ZnO}$ & 2 & 15 W UV lamps & 90 & 20 & 7 & 57 & This study \\
\hline $\mathrm{Cu} . \mathrm{Mn}$-doped $\mathrm{ZnO}$ & 2 & Sunlight & 90 & 20 & 7 & 74 & This study \\
\hline $\mathrm{Cu} . \mathrm{Mn}$-doped $\mathrm{ZnO}$ & 2 & Elma ultrasonic bath- 37 and $80 \mathrm{kHz}$ & 90 & 20 & 7 & $60 / 62$ & This study \\
\hline $\mathrm{Cu} . \mathrm{Mn}$-doped $\mathrm{ZnO}$ & 2 & 20-watt LED lamp & 90 & 20 & 7 & 70 & This study \\
\hline
\end{tabular}

3.2.2. Humic Acid Concentration. Figure 10(b) demonstrates the effects of pollutant concentration on the photocatalytic removal of humic acid. As can be seen, the removal efficiency decreased with increasing the content of humic acid. We observed the highest removal efficiency at $5 \mathrm{mg} / \mathrm{L}$ of humic acid after $120 \mathrm{~min}$ of reaction time. Moreover, the lowest removal efficiency was obtained at $50 \mathrm{mg} / \mathrm{L}$ of the pollutant after $60 \mathrm{~min}$ of reaction, which shows that the high concentration of humic acid can obviously decrease the process efficiency. Each catalyst has a determined capacity for photocatalytic degradation of pollutant molecules on its surface; hence, a notable increase in the pollutant concentration can decrease their performance and efficiency [55].

3.2.3. Effect of Nanocatalyst Dosage. In the present study, we evaluated the effects of the nanocatalyst dosage on the photocatalysis of humic acid at different contact times (Figure 10(c)). We observed the lowest removal efficiency of humic acid at $0.4 \mathrm{~g} / \mathrm{L}$ dosage of the $\mathrm{ZnO}$ nanoparticles. In contrast, we observed the highest removal efficiency of this organic matter in $8 \mathrm{~g} / \mathrm{L}$ dosage of the proposed nanocatalyst. We conclude that a higher amount of nanocatalyst can increase the process capacity for the removal of a high concentration of humic acid.

3.2.4. Effect of Contact Time. Here, we have shown that increasing contact time from 60 to $120 \mathrm{~min}$ significantly improved the process performance for the removal and oxidation of humic acid during the proposed photocatalytic process. In addition, we separately evaluated the effect of different contact times on the process efficiency. Figure 10(d) shows the trends of performance changes of the proposed process by increasing contact time. As can be seen here, the efficiency of the proposed photocatalyst process continually increased with increasing contact time, which implied that we can achieve the desired performance for a high concentration of humic acid by using a high contact time. We can attribute this result to the effect of UV light during the proposed process that can further affect the catalyst surface by decreasing humic acid concentration during the reaction. We should point out that the findings obtained in this study are consistent with previous studies on the removal of various pollutants using photocatalytic processes $[56,57]$. In agreement with our study, for example, Rashid Khan et al. stated that $\mathrm{Cu}-\mathrm{ZnO}$ nanoparticle could reach a suitable performance in reactive red S3 B dye removal after a reaction time of $100 \mathrm{~min}$ and they concluded that the $\mathrm{Cu}-\mathrm{ZnO}$ catalyst was entirely effective [58].

3.3. Mineralization of HAs. Regarding the HAs degradation, it is clear that the addition of dopants strongly enhances the degradation of HAs. In general, the photocatalytic oxidation process is based on the formation of reactive oxygen species (ROSs) including $\mathrm{h}^{+}, \bullet \mathrm{OH}$, and $\mathrm{O}_{2}{ }_{2}^{-}$. ROS are very powerful oxidants that have the ability to degrade many organic compounds [59, 60]. Principally, if ZnO NPs are excited by exposure to an energy source such as visible light or ultraviolet light, $\mathrm{h}^{+}{ }_{\mathrm{VB}}$ and conduction band (CB) electron pairs are produced. Then, a set of reactions take place, resulting in the formation of the radicals of $\bullet \mathrm{OH}$ and $\mathrm{O}_{2}{ }_{2}^{-}$. The formed radicals can attack organic materials on the surface of $\mathrm{ZnO}[60,61]$. In fact, during the process, there are three distinct pathways for HA degradation, which generally include oxidation by hydroxyl radicals, reduction by superoxide radicals, and adsorption by the catalyst [60]. As a result, organic materials are 

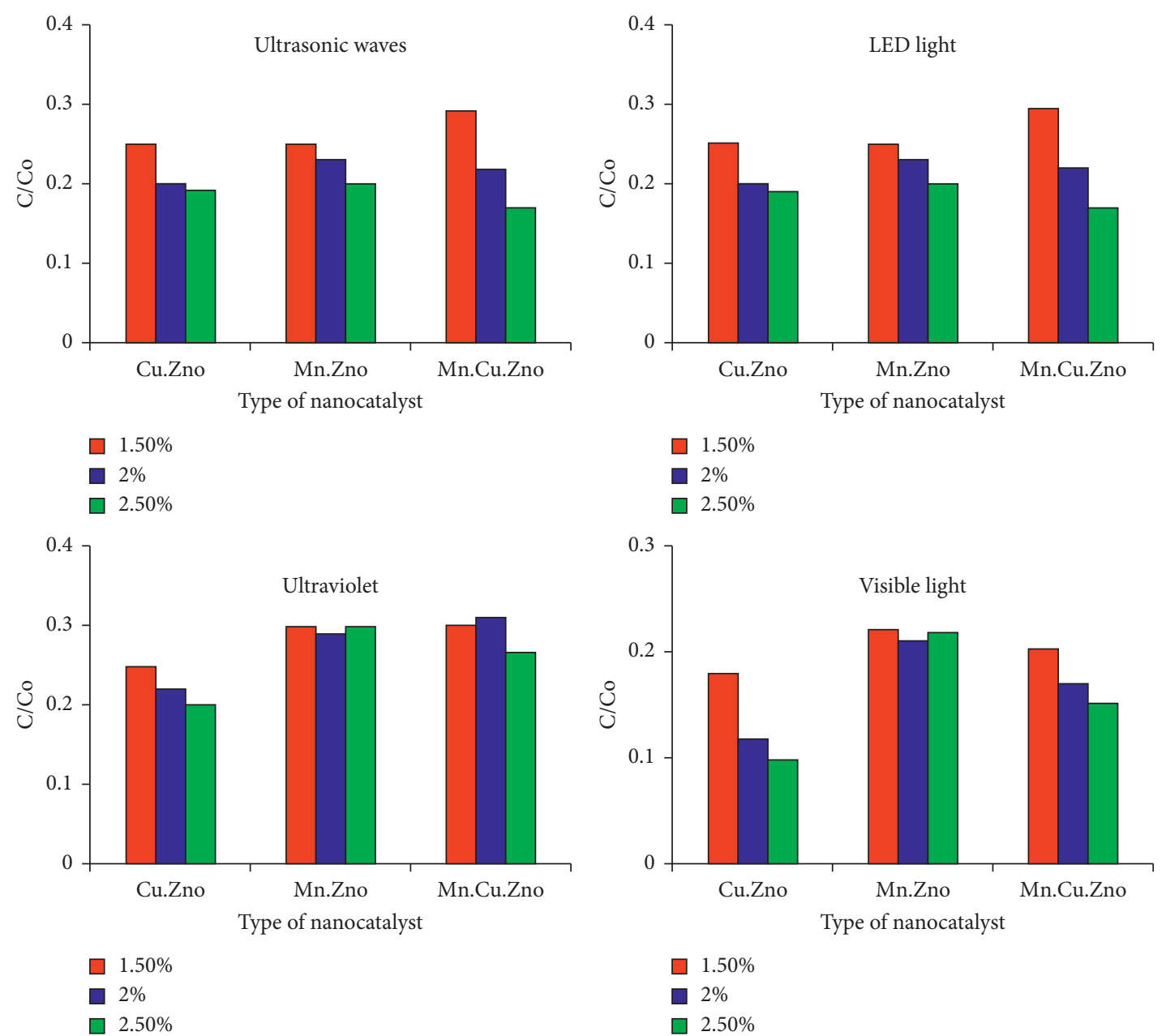

FIgURE 9: Effect of dopant percentage on degradation efficiency of humic acid under different synthesized nanoparticles and processes: contact time $=90 \mathrm{~min}$, humic acid concentration $=10 \mathrm{mg} / \mathrm{L}, \mathrm{pH}=7$, dosage $=2 \mathrm{~g} / \mathrm{L}$.

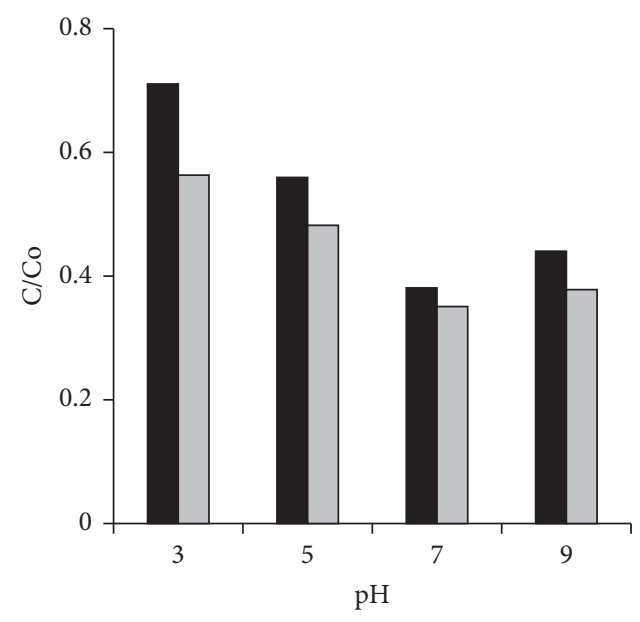

- $60 \mathrm{~min}$ $\square 120 \mathrm{~min}$

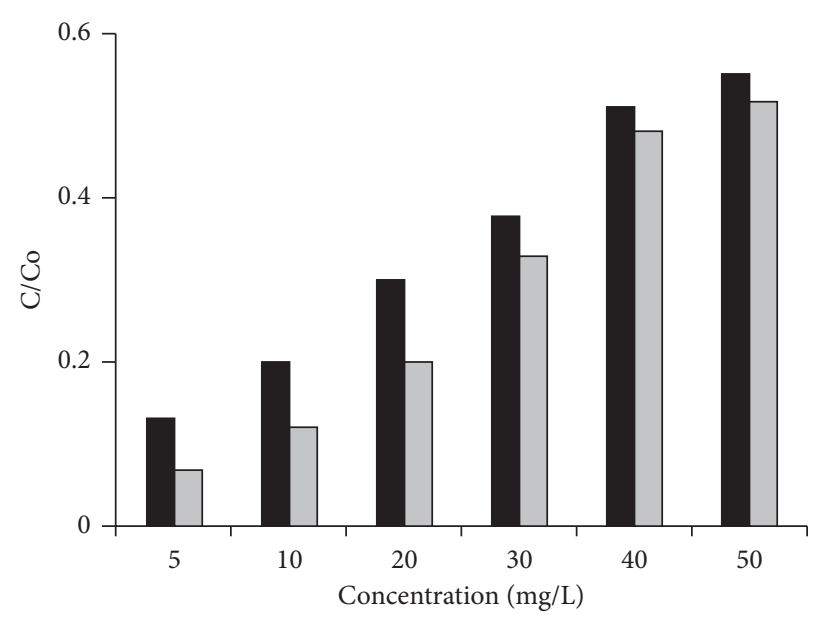

- $60 \mathrm{~min}$

$\square 120 \mathrm{~min}$

(a)

Figure 10: Continued. 


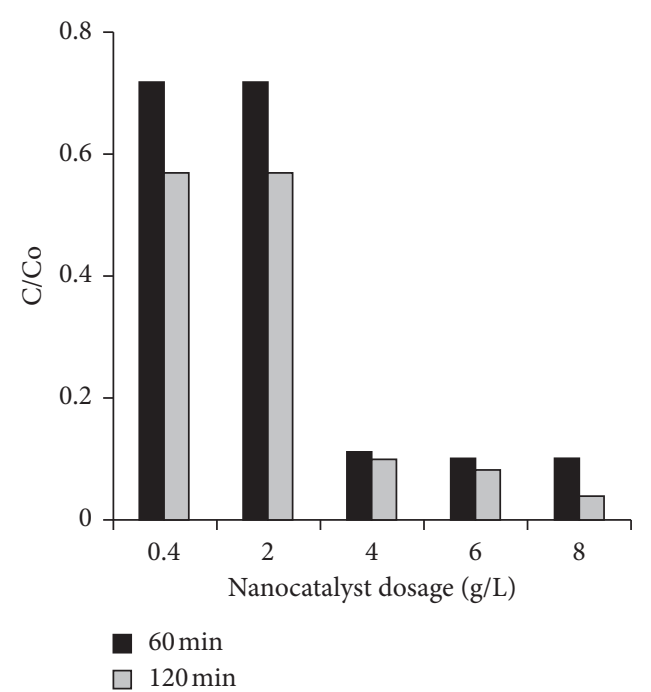

(c)

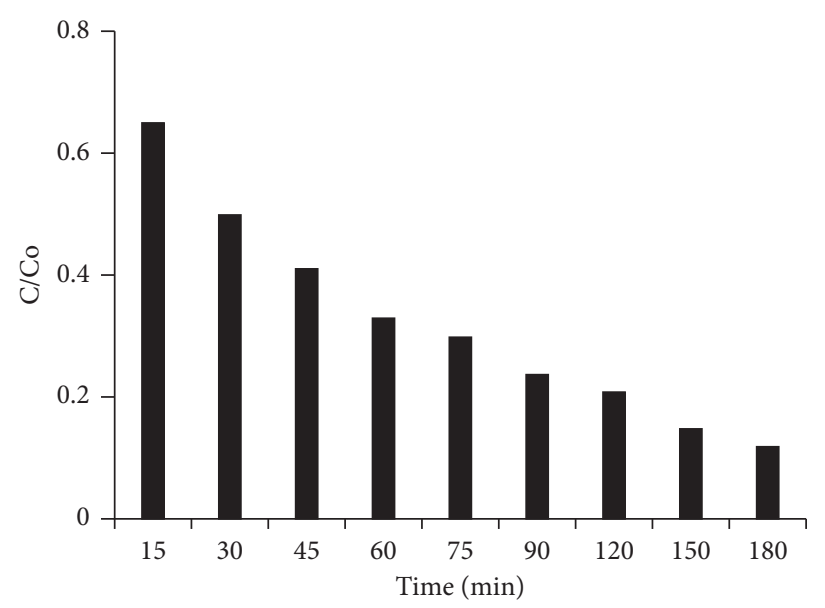

(d)

Figure 10: Effects of various operational parameters: (a) solution $\mathrm{pH}$ (contact time $=90 \mathrm{~min}$, humic acid concentration $=30 \mathrm{mg} / \mathrm{L}$, dosage $=2 \mathrm{~g} / \mathrm{l}$, dopant percentage $2 \%$ ) under the presence of $\mathrm{VL}$, (b) pollutant concentration $(\mathrm{pH}=7$, dopant percentage $2 \%$, dosage $=2 \mathrm{~g} / \mathrm{l}$ ) under the presence of $\mathrm{VL}$, (c) nanocatalyst dosage (contact time $=90 \mathrm{~min}$, humic acid concentration $=20 \mathrm{mg} / \mathrm{L}, \mathrm{pH}=7$, dopant percentage $=2 \%$ ) under the presence of $\mathrm{VL}$, and $(\mathrm{d}$ ) contact time (humic acid concentration $=20 \mathrm{mg} / \mathrm{L}, \mathrm{pH}=7$, dopant percentage $2 \%$, dosage $=2 \mathrm{~g} / \mathrm{l}$ ) under the presence of $\mathrm{VL}$ on photocatalysis of humic acid using the Cu.ZnO PNs.

degraded and final products including $\mathrm{H}_{2} \mathrm{O}$ and $\mathrm{CO}_{2}$ are produced. Of course, due to the incomplete mineralization process, it will usually be possible to produce intermediate products. Therefore, it was claimed that the reaction between $\mathrm{HA}$ and reactive oxygen species could produce carboxylic acids with low molecular weights such as oxalic, succinic, formic, acetic, and malonic acids [59,60]. It should be noted that doping can help produce more $\mathrm{OH}$ radicals, therefore, leading to higher degradation efficiency of organic pollutants. This is because $\mathrm{Cu}$ and $\mathrm{Mn}$ act as electron scavengers and prevent the recombination of electron-hole pairs [61].

\section{Conclusion}

The characterization tests illustrated that the synthesized $\mathrm{Cu} . \mathrm{ZnO}$ nanoparticles were well-crystalline and benefited from suitable optical properties. Also, we found out that the photocatalytic performance of the $\mathrm{Cu} . \mathrm{ZnO}$ nanoparticles was better than that of the $\mathrm{ZnO}$ nanoparticles. The degradation rate raised with enhancing the concentration of $\mathrm{Cu}$ doping up to $2.5 \%$. The photocatalytic processes exhibited better performance in HS removal than the sonocatalytic processes. And, among all methods examined in the current research, Cu.ZnO, Mn.ZnO, and Mn.Cu.ZnO in the presence of VL irradiation had the highest removal performance. In conclusion, $\mathrm{Cu} . \mathrm{ZnO}$ nanoparticles under $\mathrm{VL}$ irradiation can be applied as an efficient nanocatalyst for the removal of humic substances.

\section{Data Availability}

The data used to support the findings of this study are included within the article.

\section{Conflicts of Interest}

The authors declare that they have no conflicts of interest.

\section{Acknowledgments}

The research reported in this publication was supported by Elite Researcher Grant Committee (Award no. 982747) from the National Institutes for Medical Research Development (NIMAD), Tehran, Iran.

\section{References}

[1] M. Kleber and J. Lehmann, "Humic substances extracted by alkali are invalid proxies for the dynamics and functions of organic matter in terrestrial and aquatic ecosystems," Journal of Environmental Quality, vol. 48, no. 2, pp. 207-216, 2019.

[2] S. Valencia, J. M. Marín, G. Restrepo, and F. H. Frimmel, "Application of excitation-emission fluorescence matrices and UV/Vis absorption to monitoring the photocatalytic degradation of commercial humic acid," Science of the Total Environment, vol. 442, pp. 207-214, 2013.

[3] A. R. Yazdanbakhsh and Y. Hashempour, "Experimental design and response surface modeling for optimization of humic substances removal by activated carbon: a kinetic and isotherm study," Journal of Advances in Environmental Health Research, vol. 3, no. 2, pp. 91-101, 2015.

[4] R. Rezaee, M. Safari, R. Ghanbari, E. Ghahramani, M. Hosseini, and Y. Zandsalimi, "The simultaneous removal of turbidity and humic substances from water using the enhanced coagulation process," Journal of Advances in Environmental Health Research, vol. 5, no. 2, pp. 85-92, 2017.

[5] H. Hossini, M. Safari, R. Rezaee, R. Darvishi Cheshmeh Soltani, O. Giahi, and Y. Zandsalimi, "Application of experimental design approach for optimization of the 
photocatalytic degradation of humic substances in aqueous solution using immobilized $\mathrm{ZnO}$ nanoparticles," Journal of Advances in Environmental Health Research, vol. 3, no. 3, pp. 154-163, 2015.

[6] X. Zhang and R. A. Minear, "Formation, adsorption and separation of high molecular weight disinfection byproducts resulting from chlorination of aquatic humic substances," Water Research, vol. 40, no. 2, pp. 221-230, 2006.

[7] A. Li, X. Zhao, H. Liu, and J. Qu, "Characteristic transformation of humic acid during photoelectrocatalysis process and its subsequent disinfection byproduct formation potential," Water Research, vol. 45, no. 18, pp. 6131-6140, 2011.

[8] G. Hasani, A. Maleki, H. Daraei et al., "A comparative optimization and performance analysis of four different electrocoagulation-flotation processes for humic acid removal from aqueous solutions," Process Safety and Environmental Protection, vol. 121, pp. 103-117, 2019.

[9] J. Lowe and M. M. Hossain, "Application of ultrafiltration membranes for removal of humic acid from drinking water," Desalination, vol. 218, no. 1-3, pp. 343-354, 2008.

[10] M.-Y. Chang and R.-S. Juang, "Adsorption of tannic acid, humic acid, and dyes from water using the composite of chitosan and activated clay," Journal of Colloid and Interface Science, vol. 278, no. 1, pp. 18-25, 2004.

[11] Y. Deng and R. Zhao, "Advanced oxidation processes (AOPs) in wastewater treatment," Current Pollution Reports, vol. 1, no. 3, pp. 167-176, 2015.

[12] R. Darvishi Cheshmeh Soltani, A. Rezaee, R. Rezaee, M. Safari, and H. Hashemi, "Photocatalytic degradation of methylene blue dye over immobilized $\mathrm{ZnO}$ nanoparticles: optimization of calcination conditions," Journal of Advances in Environmental Health Research, vol. 3, no. 1, pp. 8-14, 2015.

[13] R. D. C. Soltani, M. Safari, and M. J. U. S. Mashayekhi, "Sonocatalyzed decolorization of synthetic textile wastewater using sonochemically synthesized MgO nanostructures," Ultrasonics Sonochemistry, vol. 30, pp. 123-131, 2016.

[14] H. Hu, H. Zhang, Y. Chen, Y. Chen, L. Zhuang, and H. Ou, "Enhanced photocatalysis degradation of organophosphorus flame retardant using MIL-101(Fe)/persulfate: effect of irradiation wavelength and real water matrixes," Chemical Engineering Journal, vol. 368, pp. 273-284, 2019.

[15] Y. Zandsalimi, A. Mohseni-Bandpei, H. Daraei, L. Alaei, and S. W Joo, "Application of artificial intelligent approaches for the efficiency and energy consumption of a novel sonocatalyst," Journal of Advances in Environmental Health Research, vol. 4, no. 4, pp. 213-218, 2016.

[16] A. Maleki, M. Safari, B. Shahmoradi, Y. Zandsalimi, H. Daraei, and F. Gharibi, "Photocatalytic degradation of humic substances in aqueous solution using $\mathrm{Cu}$-doped $\mathrm{ZnO}$ nanoparticles under natural sunlight irradiation," Environmental Science and Pollution Research, vol. 22, no. 21, pp. 16875-16880, 2015.

[17] Y. Zandsalimi, P. Taymori, R. Darvishi Cheshmeh Soltani, R. Rezaee, N. Abdullahi, and M. Safari, "Photocatalytic removal of Acid Red 88 dye using zinc oxide nanoparticles fixed on glass plates," Journal of Advances in Environmental Health Research, vol. 3, no. 2, pp. 102-110, 2015.

[18] M. M. Ba-Abbad, A. A. H. Kadhum, A. B. Mohamad, M. S. Takriff, and K. Sopian, "Visible light photocatalytic activity of $\mathrm{Fe} 3+-$ doped $\mathrm{ZnO}$ nanoparticle prepared via sol-gel technique," Chemosphere, vol. 91, no. 11, pp. 1604-1611, 2013.

[19] S. Saeedi, H. Godini, M. Almasian et al., "Photocatalytic degradation of phenol in water solutions using $\mathrm{ZnO}$ nanoparticles immobilized on glass," Journal of Advances in Environmental Health Research, vol. 3, no. 3, pp. 204-213, 2015.

[20] R. Saleh and N. F. Djaja, "Transition-metal-doped ZnO nanoparticles: synthesis, characterization and photocatalytic activity under UV light," Spectrochimica Acta Part A: Molecular and Biomolecular Spectroscopy, vol. 130, pp. 581-590, 2014.

[21] Y. Zandsalimi, B. Shahmoradi, S. Dehestani Athar, and A. Maleki, "Hydrothermal synthesis and characterization of Tungsten-doped $\mathrm{ZnO}$ nanoparticles as an environmentally friendly substance," Journal of Advances in Environmental Health Research, vol. 6, no. 3, pp. 173-178, 2018.

[22] X. Wang, X. Zhang, Y. Zhang et al., "Nanostructured semiconductor supported iron catalysts for heterogeneous photoFenton oxidation: a review," Journal of Materials Chemistry A, vol. 8, no. 31, pp. 15513-15546, 2020.

[23] R. A. Nyquist and R. O. Kagel, Handbook of Infrared and Raman Spectra of Inorganic Compounds and Organic Salts: Infrared Spectra of Inorganic Compounds, Academic Press, Cambridge, MA, USA, 2012.

[24] K. Linden and M. Mohseni, Advanced Oxidation Processes: Applications in Drinking Water Treatment, Springer, Berlin, Germany, 2014.

[25] A. J. Reddy, M. K. Kokila, H. Nagabhushana et al., "Structural, optical and EPR studies on $\mathrm{ZnO}: \mathrm{Cu}$ nanopowders prepared via low temperature solution combustion synthesis," Journal of Alloys and Compounds, vol. 509, no. 17, pp. 5349-5355, 2011.

[26] C. Sushma and S. Girish Kumar, "Advancements in the zinc oxide nanomaterials for efficient photocatalysis," Chemical Papers, vol. 71, no. 10, pp. 2023-2042, 2017.

[27] C.-J. Chang, C.-Y. Lin, and M.-H. Hsu, "Enhanced photocatalytic activity of Ce-doped $\mathrm{ZnO}$ nanorods under $\mathrm{UV}$ and visible light," Journal of the Taiwan Institute of Chemical Engineers, vol. 45, no. 4, pp. 1954-1963, 2014.

[28] B. Subash, B. Krishnakumar, R. Velmurugan, M. Swaminathan, and M. Shanthi, "Synthesis of Ce co-doped Ag-ZnO photocatalyst with excellent performance for NBB dye degradation under natural sunlight illumination," $\mathrm{Ca}$ talysis Science \& Technology, vol. 2, no. 11, pp. 2319-2326, 2012.

[29] H. Eskandarloo, A. Badiei, M. A. Behnajady, A. Tavakoli, and G. M. Ziarani, "Ultrasonic-assisted synthesis of Ce doped cubic-hexagonal $\mathrm{ZnTiO} 3$ with highly efficient sonocatalytic activity," Ultrasonics Sonochemistry, vol. 29, pp. 258-269, 2016.

[30] X. Liu, Z. Guan, H. L. Liu et al., "Synthesis and characterization of polymer-laced $\mathrm{Cu}-\mathrm{ZnO}$ nanoparticles," Advanced Materials Research, pp. 138-141, Trans Tech Publications, Stafa-Zurich, Switzerland, 2015.

[31] S. Muthukumaran and R. Gopalakrishnan, "Structural, FTIR and photoluminescence studies of $\mathrm{Cu}$ doped $\mathrm{ZnO}$ nanopowders by co-precipitation method," Optical Materials, vol. 34, no. 11, pp. 1946-1953, 2012.

[32] M. Samadi, M. Zirak, A. Naseri, E. Khorashadizade, and A. Z. Moshfegh, "Recent progress on doped $\mathrm{ZnO}$ nanostructures for visible-light photocatalysis," Thin Solid Films, vol. 605, pp. 2-19, 2016.

[33] T. L. Tan, C. W. Lai, and S. B. Abd Hamid, "Tunable band gap energy of $\mathrm{Mn}$-doped $\mathrm{ZnO}$ nanoparticles using the coprecipitation technique," Journal of Nanomaterials, vol. 2014, 2014.

[34] Y. Wang, J. Cheng, S. Yu et al., "Synergistic effect of $\mathrm{N}$-decorated and $\mathrm{Mn} \mathrm{2+}$ doped $\mathrm{ZnO}$ nanofibers with 
enhanced photocatalytic activity," Scientific Reports, vol. 6, no. 1, pp. 1-10, 2016.

[35] K. Raja, P. S. Ramesh, and D. Geetha, "Structural, FTIR and photoluminescence studies of Fe doped $\mathrm{ZnO}$ nanopowder by co-precipitation method," Spectrochimica Acta Part A: Molecular and Biomolecular Spectroscopy, vol. 131, pp. 183-188, 2014.

[36] N. M. Shamhari, B. S. Wee, S. F. Chin, and K. Y. Kok, "Synthesis and characterization of zinc oxide nanoparticles with small particle size distribution," Acta Chimica Slovenica, vol. 65 , no. 3, pp. 578-585, 2018.

[37] A. K. Zak, R. Razali, W. H. Majid, and M. Darroudi, "Synthesis and characterization of a narrow size distribution of zinc oxide nanoparticles," International Journal of Nanomedicine, vol. 6, pp. 1399-403, 2011.

[38] M. Gupta, R. S. Tomar, S. Kaushik, R. K. Mishra, and D. Sharma, "Effective antimicrobial activity of green $\mathrm{ZnO}$ nano particles of Catharanthus roseus," Frontiers in Microbiology, vol. 9, Article ID 2030, 2018.

[39] R. Yuan, D. Liu, S. Wang, B. Zhou, and F. Ma, "Enhanced photocatalytic oxidation of humic acids using Fe 3+-Zn 2+ codoped TiO 2: the effects of ions in aqueous solutions," Environmental Engineering Research, vol. 23, no. 2, pp. 181-188, 2018.

[40] S. Gueu, G. Finqueneisel, T. Zimny, B. K. Yao, and J. S. O.-A. Chim, "Photocatalytic degradation of humic acid using TiO2 in aqueous solution," Journal de la Société OuestAfricaine de Chimie, vol. 48, pp. 19-25, 2019.

[41] H. Moein, G. Nabi Bidhendi, N. Mehrdadi, and H. Kamani, "Efficiency of photocatalytic degradation of humic acid using magnetic nanoparticles (Fe-doped TiO 2@ Fe $3 \mathrm{O}$ 4) in aqueous solutions," Health Scope, vol. 9, no. 2, 2020.

[42] H. Kamani, S. Nasseri, M. Khoobi, R. N. Nodehi, and A. H. Mahvi, "Sonocatalytic degradation of humic acid by $\mathrm{N}$-doped TiO 2 nano-particle in aqueous solution," Journal of Environmental Health Science and Engineering, vol. 14, no. 1, pp. 1-9, 2016.

[43] R. D. C. Soltani, M. Safari, R. Rezaee, A. Maleki, O. Giahi, and R. Ghanbari, "Sonocatalytic degradation of humic substances from aquatic environments using $\mathrm{MgO}$ nanoparticles," Avicenna Journal of Environmental Health Engineering, vol. 4, no. 2, pp. 13-18, 2017.

[44] M. T. Ghaneian, P. Morovati, M. H. Ehrampoush, and M. Tabatabaee, "Humic acid degradation by the synthesized flower-like $\mathrm{Ag} / \mathrm{ZnO}$ nanostructure as an efficient photocatalyst," Journal of Environmental Health Science and Engineering, vol. 12, no. 1, pp. 1-7, 2014.

[45] J. Y. So and D. S. Rhee, Photocatalytic Degradation of Humic Acid with Metal-Doped TiO2 Under Near-Visible Irradiation, Key Engineering Materials, pp. 589-593, Trans Tech Publications, Stafa-Zurich, Switzerland, 2017.

[46] M. A. Zulfikar, A. D. Chandra, H. Setiyanto, N. Handayani, and D. Wahyuningrum, "TiO 2/ZnO nanocomposite photocatalyst: synthesis, characterization and their application for degradation of humic acid from aqueous solution," Songklanakarin Journal of Science \& Technology, vol. 42, no. 2, 2020.

[47] J. V. Hernandez, Structural and Morphological modification of TiO2 doped metal ions and investigation of photo-induced charge transfer processes, Université du Maine; Instituto politécnico nacional (México), México, 2017.

[48] T. Nguyen Thi Thu, N. Nguyen Thi, V. Tran Quang, K. Nguyen Hong, T. Nguyen Minh, and N. Le Thi Hoai, "Synthesis, characterisation, and effect of $\mathrm{pH}$ on degradation of dyes of copper-doped TiO2," Journal of Experimental Nanoscience, vol. 11, no. 3, pp. 226-238, 2016.

[49] A. Taufik, A. Albert, and R. Saleh, "Sol-gel synthesis of ternary $\mathrm{CuO} / \mathrm{TiO} 2 / \mathrm{ZnO}$ nanocomposites for enhanced photocatalytic performance under UV and visible light irradiation," Journal of Photochemistry and Photobiology A: Chemistry, vol. 344, pp. 149-162, 2017.

[50] N. Geng, W. Chen, H. Xu, M. Ding, Z. Liu, and Z. Shen, "A sono-photocatalyst for humic acid removal from water: operational parameters, kinetics and mechanism," Ultrasonics Sonochemistry, vol. 57, pp. 242-252, 2019.

[51] A. Seid-Mohammadi, A. Gh, M. Sammadi, M. Ahmadian, and A. Poormohammadi, "Removal of humic acid from synthetic water using chitosan as coagulant aid in electrocoagulation process for $\mathrm{Al}$ and $\mathrm{Fe}$ electrodes," Research Journal of Chemistry and Environment, vol. 18, p. 5, 2014.

[52] J. Wiszniowski, D. Robert, J. Surmacz-Gorska, K. Miksch, and J.-V. Weber, "Photocatalytic mineralization of humic acids withTiO2: effect of $\mathrm{pH}$, sulfate and chloride anions," International Journal of Photoenergy, vol. 5, no. 2, pp. 69-74, 2003.

[53] M. Kosmulski, "pH-dependent surface charging and points of zero charge," Journal of Colloid and Interface Science, vol. 298, no. 2, pp. 730-741, 2006.

[54] M. N. Zafar, Q. Dar, F. Nawaz, M. N. Zafar, M. Iqbal, and M. F. Nazar, "Effective adsorptive removal of azo dyes over spherical ZnO nanoparticles," Journal of Materials Research and Technology, vol. 8, no. 1, pp. 713-725, 2019.

[55] P. Chandran, S. Netha, and S. Sudheer Khan, "Effect of humic acid on photocatalytic activity of $\mathrm{ZnO}$ nanoparticles," Journal of Photochemistry and Photobiology B: Biology, vol. 138, pp. 155-159, 2014.

[56] S. Rahimi, A. Poormohammadi, B. Salmani, M. Ahmadian, and M. Rezaei, "Comparing the photocatalytic process efficiency using batch and tubular reactors in removal of methylene blue dye and COD from simulated textile wastewater," Journal of Water Reuse and Desalination, vol. 6, no. 4, pp. 574-582, 2016.

[57] R. Yuan, B. Zhou, D. Hua, and C. Shi, "Enhanced photocatalytic degradation of humic acids using $\mathrm{Al}$ and $\mathrm{Fe}$ co-doped $\mathrm{TiO} 2$ nanotubes under UV/ozonation for drinking water purification," Journal of Hazardous Materials, vol. 262, pp. 527-538, 2013.

[58] H. R. Khan, G. Murtaza, M. A. Choudhary, Z. Ahmed, and M. A. Malik, "Photocatalytic removal of carcinogenic reactive red $\mathrm{S} 3 \mathrm{~B}$ dye by using $\mathrm{ZnO}$ and $\mathrm{Cu}$ doped $\mathrm{ZnO}$ nanoparticles synthesized by polyol method: a kinetic study," Solar Energy, vol. 173, pp. 875-881, 2018.

[59] T. T. Nguyen, S.-N. Nam, J. Kim, and J. Oh, "Photocatalytic degradation of dissolved organic matter under $\mathrm{ZnO}$-catalyzed artificial sunlight irradiation system," Scientific Reports, vol. 10, no. 1, pp. 1-12, 2020.

[60] T. Thi Nguyen and S.-N. Nam, "Sunlight-driven photocatalysis of dissolved organic matter: tracking by excitation emission matrix-parallel factor analysis and optimization using response surface methodology," Environmental Engineering Research, vol. 26, no. 3, Article ID 200201, 2020.

[61] C. B. Ong, L. Y. Ng, and A. W. Mohammad, "A review of $\mathrm{ZnO}$ nanoparticles as solar photocatalysts: synthesis, mechanisms and applications," Renewable and Sustainable Energy Reviews, vol. 81, pp. 536-551, 2018. 